\title{
CONTRIBUIÇÕES FOUCAULTIANAS PARA A CONSTITUIÇÃO FORMATIVA DO SUJEITO
}

\author{
MARCELO FURLIN* \\ JOSÉ PASCOAL MANTOVANI**
}

\begin{abstract}
RESUMO
$\mathrm{O}$ artigo apresenta a filosofia de Michel Foucault (VEIGA-NETO, 2004) aplicado à epistemologia da Educação, na inspiração de que os domínios focaultianos proporcionam instrumentais teóricos e práticos para a construção de um novo sujeito no processo formativo. Três são os objetivos do breve estudo: (i) apresentar, resumidamente, os domínios focaultianos (VEIGA-NETO, 2004) e sua relação com a formação do sujeito (REVEL, 2002); (ii) descrever os conceitos foucaultianos sobre subjetividade, filosofia e espiritualidade e (iii) articular algumas contribuições da Filosofia contemporânea. voltadas à prática educativa, no que se referem à constituição do sujeito contemporâneo. $\mathrm{O}$ corpus selecionado para a pesquisa são referências bibliográficas de e sobre Foucault, bem como demandas contemporâneas relacionadas à
\end{abstract}

* Doutor em Letras pela Universidade de São Paulo (USP) e Mestre em Comunicação e Letras pela Universidade Presbiteriana Mackenzie. Coordenador do Programa de Pós-Graduação em Educação da Universidade Metodista de São Paulo (UMESP). Pesquisador do Grupo de Pesquisa sobre a Abordagem Hermenêutico-Fenomenológica e Complexidade (GPeAHFC) da Pontifícia Universidade Católica de São Paulo (PUC-SP). E-mail: marcelo. furlin@metodista.br

** Graduado em Filosofia e Teologia, Mestre em Ciências da Religião e Doutorando em Educação pelo Programa de Pós-Graduação da UMESP, sob a orientação do prof. Dr. Marcelo Furlin. Coordenador do Grupo de Estudos 'DOMAINE: Foucault em perspectiva' na UMESP. Professor de filosofia no Ensino Básico e Superior. Título da Tese em andamento:: Educar sem (de) formar: contribuições foucaultianas para a constituição narrativa do sujeito. Orientador: Prof. Dr. Marcelo Furlin. E-mail: jose.junior20@metodista.br. 
filosofia da educação. O repertório teórico que fundamentam este trabalho são os textos de Michel Foucault (2005; 2006; 2010a) que remetem à hermenêutica do sujeito. No que tange à teoria foucaultiana serão utilizadas as reflexões de Veiga-Neto (2004), Revel (2002) e Machado (2007).

Palavras-chave: Michel Foucault; Educação; Hermenêutica do sujeito

\title{
FOUCAULTIAN CONTRIBUTIONS TO THE FORMATIVE CONSTITUTION OF THE SUBJECT
}

\begin{abstract}
In this article, the philosophy of Michel Foucault (VEIGA-NETO, 2004) is interwoven with the epistemology of education, in the sense that the Foucaultian domains pave the way for human formative processes. The objectives are threefold: (i) to briefly present the Foucaultian domains; (ii) to describe Foucaultian concepts regarding subjectivity and (iii) to offer contributions of the contemporary philosophy towards education. Bibliographical references by and about Foucault outline the corpus for the research, inspired by the philosophy of education. The study is based on Hermeneutics-related texts by Michel Foucault. As to the Foucaultian theory, reflections by Veiga-Neto (2004), Revel (2002) and Machado (2007) are considered.
\end{abstract}

Key words: Michel Foucault; Education; Hermeneutics of the subject

\section{INTRODUÇÃO}

Os domínios de Michel Foucault são instrumentais técnicos e teóricos relevantes para a área das ciências humanas porque demonstram, textualmente, a mimesis da prática educacional em suas mais diversas relações. Mais do que apontar caminhos, as teorias foucaultianas são capazes de auxiliar na criação de novas alternativas que superam os moldes tradicionais de ensino-aprendizagem, isto é, há uma superação do patamar rígido e arbitrário do docente em reação ao discente, que assume função coadjutora no processo formativo. Em vez de apontar uma rota 
cômoda, pré-estabelecida, as teorias foucaultianas são como tratores que percebem nas menores fissuras oportunidades singulares para reinventar a constituição do sujeito no mundo em que está inserido.

Este artigo está divido em três partes. A primeira apresenta algumas ideias basilares dos três domínios do filósofo Francês Michel Foucault (2006). Como ele é autor de uma imensa obra, é possível segmentar o conhecimento em três domínios específicos de conhecimento, a saber: a arqueologia, a genealogia e a ética (conceitos que serão definidos posteriormente). Antes, contudo, vale destacar que os domínios foucaultianos não são uma teoria linear ou de superação, em vez disso, são instrumentais teóricos sobre o mesmo objeto de pesquisa: o ser humano.

A segunda parte deste artigo descreve três termos importantes na filosofia foucaultiana (2004) no que se refere à construção e interpretação do sujeito em categorias Foucaultianas (2004). A subjetividade (que é a maneira do sujeito experienciar a si mesmo), o conceito de filosofia (a reflexão sobre as possibilidades de verdade) e a espiritualidade (como ação transcendental para alcançar a verdade), Esses termos descrevem ferramentas valiosas para que o sujeito consiga superar as heteronomias leis externas e sociais normalizadoras das condutas - para uma ação autônoma e emancipada. Por fim, a terceira parte discute a articulação de ideias foucaultianas com demandas contingenciais presentes no âmbito da formação de docentes.

Aproximar as teorias de Foucault (2006) não significa apenas um esforço de análise arqueológica de mazelas, erros e problemas da educação brasileira - haja vista que a crise da educação brasileira contemporânea foi um projeto bem-sucedido (RIBEIRO, 2015). Em vez disso, Foucault (2010a) aponta meios de enfrentamento e ressignificação das metodologias consolidadas que tangenciam o fenômeno educacional.

\section{1 - OS DOMÍNIOS FOUCAULTIANOS}

As provocações filosóficas de Michel Foucault (2006) têm como marca identitária a transdisciplinaridade. De fato, na di- 
versidade das áreas de Humanidades, é possível dialogar com escritos de Foucault para responder a alguns questionamentos emergentes. Por exemplo, há uma tendência de ler os textos de Foucault como um filósofo estruturalista, como aquele que sistematicamente sedimenta as camadas humanas e sociais e que propõe uma hermenêutica crítica; seus textos que tratam das relações de poder, punições e controle fazem parte da bibliografia de cursos de Direito $^{1}$ e também das licenciaturas de Pedagogia; há, também, aqueles que preferem ler Foucault a partir das relações intersubjetivas, a sua teorização sobre a sexualidade presentes em boa parte de seus escritos. Invariavelmente, em qualquer de suas obras, o ser-sujeito ou tornar-se sujeito é sempre a base analítica das metodologias foucaultianas.

A partir da fundamentação teórica de que o 'sujeito'/ser é o cerne de toda obra foulcaultina, seguindo as proposições de Veiga-Neto (2004, p. 35), é possível dividir sua obra em três etapas distintas, ou em três domínios. Falar de domínios não é negar uma fase em detrimento de outra; trata-se, sobretudo, de demonstrar a relação entre o conteúdo epistêmico que o filósofo apresentou de modo dialético em toda a sua construção teórica, considerando o sujeito como eixo arqueológico.

Com vistas metodológicas, apresentaremos os três enfoques de Foucault: (i) a arqueologia; (ii) a genealogia, (iii) e a ética. Segundo Veiga-Neto, "Foucault dividiu em três modos a subjetivação de tornar os humanos em sujeitos: a arqueologia, a genealogia e a ética" (2004, p. 36). Na primeira fase é possível perceber um Foucault com rudimentos estruturalistas. Sua preocupação é em decodificar o ser humano a partir das estruturas que permeiam sua existência. A segunda fase, entrelaçada com a primeira, é marcada pela gênese do poder, uma relação que necessariamente implica, ao menos, dois sujeitos em relação: quem exerce o poder e quem se sujeita ao poder. Na terceira fase, nota-se um Foucault preocupado com o 'cuidado de si',

$\mathrm{Na}$ área de Direito os livros mais utilizados são: Vigiar e Punir: nascimento da prisão; Microfísica do Poder: Segurança, Território e população. Na pedagogia, além de Vigiar e Punir, é comum a utilização dos livros: A história da Sexualidade; História da Loucura; O Governo de Si e dos Outros 
isto é, como ser sujeito em relação consigo mesmo. O método estruturalista é suspenso e o pensador assume uma postura de hermenêutica do 'si mesmo'. Nessa direção, sintetizando as etapas de Foucault, Veiga-Neto (1996, p. 309) afirma:

Para Foucault, o homem nasce, primeiramente, para a arqueologia, tornando-se sujeito de um saber. Em seguida, não de forma linear, nasce o homem para o poder, por meio da genealogia. Por fim, o homem nasce para a ética, por meio da relação consigo mesmo.

O terceiro Foucault é extremamente denso, pois o eixo de sua pesquisa é a subjetividade do sujeito, de modo que seu compromisso é colocar em análise as relações de ser consigo e com os outros, logo, um viés ético e moral. Conforme citou Deleuze (2005, p. 99), referente à abordagem foucaultiana: “é dentro do próprio homem que é preciso libertar a vida, pois o próprio homem é uma maneira de aprisiona-la". Um caminho que tem origem em si mesmo, o que foi denominado por Foucault (2006) como o cuidado de si [epimeleiaheanton].

O desafio proposto por Foucault (2006) é que não é possível a ideia de epimeleiaheautou se não houver o gnôthiseautón, isto é, a máxima do "conhece-te a ti mesmo". Foucault (2006, p. ) afirma que o cuidado de si, mais do que estar atrelado com a ideia de conhecimento de si, fundamenta-se na ideia do autoconhecimento. Desse modo, "é bem mais como uma espécie de subordinação relativamente ao preceito do cuidado de si que se formula a regra 'conhece a ti mesmo"'. Foucault (2006, p. 7) demonstra que o anseio do cuidado de si é imperativo à ideia do conhecer a si mesmo, como segue:

...o gnôthiseautón (conhece-te a ti mesmo) aparece, de maneira bastante clara e, mais uma vez, em alguns textos significativos, no quadro mais geral da epimeléiaheautôu (cuidado de si mesmo), como uma das formas, uma das consequências, uma espécie de aplicação concreta, precisa e particular, da regra geral: é preciso que te ocupes contigo mesmo, que 
não te esqueças de ti mesmo, que tenhas cuidados consigo mesmo. É neste âmbito, como que no limite deste cuidado, que aparece e se formula a regra 'conhece-te a ti mesmo'.

Nesse trecho da obra Hermenentica do Sujeito, Foucault (2006) introduz seu pensamento sobre o cuidado de si. Para tanto, apropria-se de textos da Antiguidade, especificamente da Grécia Antiga, para fundamentar sua hipótese de cuidado de si. Na perspectiva foucaultiana, o cuidado de si é inaugurado pelos gregos.

A fim de desenvolver sua teoria, o filósofo francês demonstra alguns princípios do cuidado de si. Em primeiro lugar Foucault (2006) ressalta que, como os gregos preocupavam-se em administrar suas cidades, assim, desenvolviam práticas sobre os corpos, "são, por exemplo, as técnicas de meditação, as de memorização do passado; as de exame de consciência; as de verificação das representações na medida em que elas se apresentam ao espírito.” (FOUCAULT, 2006, p. 15). Tais práticas ou técnicas estão vinculadas com a funcionalidade das leis da cidade isto é, um poder vinculado diretamente com a produção política. Em segundo lugar, o povo grego buscava produzir a economia da cidade. Desse modo era preciso distinguir e estipular os melhores e principais meios de produção que geraria a viabilidade da pólis. Foucault (2006) problematiza um terceiro aspecto que seria o cuidado de si. Para o filósofo, é impossível refletir sobre política e economia se não houver um esforço sobre o poder em si próprio. Foucault (2006, p. 138) ressalta que 'quem pretenda governar aos outros deve governar-se a si mesmo, e portanto, ocupar-se de si. (...) o conhecimento de si.". O cuidado sobre si mesmo é algo que exige técnica e empenho, como afirma Foucault (2006): "Em toda filosofia antiga o cuidado de si mesmo foi considerado, a um tempo, como um dever e como uma técnica, uma obrigação fundamental e um conjunto de procedimentos cuidadosamente elaborados".

Para desenvolver esse poder ou esse cuidado em si mesmo, o sujeito trava uma luta consigo mesmo. O ser humano só pode constituir-se como ser livre se realizar o si próprio como campo 
de batalha, se entrar em conflito consigo, de modo que o sujeito passe a fazer sua própria força ativa. O realizar a si próprio é colocar em xeque o si próprio e, dessa maneira, quebrar as forças que determinam e se opõem sobre as forças ativas ou forças de potências (NIETZSCHE, 2011).

A título de tipificação, Foucault (2006) propõe que, na Antiguidade, Sócrates ocupou o papel de gerar inquietude na alma dos seus discípulos. Essa é a função do filósofo (mestre): perturbar os seus ouvintes para que haja o retorno a si mesmo, e, consequentemente, o cuidado de si como um fenômeno de autoconhecimento. O filósofo (mestre) ocupava essa função educativa, de transformação, de potencializar metamorfose. É por esse viés que autores como Veiga-Neto (2004), Barros (2012) e Deleuze (2005) interpretam Foucault, isto é, a jornada do retorno para si é em relação com o outro, na linguagem foucaultiana: o mestre.

O cuidado de si (epimeleiaheatou) era o objetivo desse processo de mudança. Para Foucault (2006) é possível identificar ao menos três fases desse cuidado: (1) o momento socrático, em que a exigência do cuidado de si faz sua aparição na reflexão filosófica ${ }^{2}$; (2) a etapa de ouro do 'cuidado de si’3 $^{\text {; }}$ (3) a passagem

2 Como não faz parte da pretensão conceitual deste artigo apresentar as especificidades do cuidado de si, valem algumas informações basilares. Ao que se refere à primeira etapa do cuidado de si, Foucault relaciona com o período socrático. O momento socrático-platônico,, observa Foucault (ANO), caracteriza-se, precisamente, por um paradoxo: a subordinação do cuidado de si ao conhecimento de si. Esse conhecimento, é necessário sublinhá-lo, não tem, contudo, nem a forma nem o conteúdo da hermenêutica cristã do sujeito.

3 A segunda etapa é a idade de ouro do 'cuida-te a ti mesmo', nos séculos I e II (desde o estoicismo romano, representando por Musonius Rufus, até Marco Aurélio). O que Foucault chama de período de ouro, pois o que motiva o sujeito a pensar sobre si não são as contingências externas, sendo elas quaisquer que sejam (adultidade, política), em vez disso, são as orientações para o governo de si mesmo, em uma direção ética (FOUCAULT, ANO, p. 138). Para o cuidado de si há um esforço maior de técnica, de conhecimento, por isso que Foucault afirma que "o cuidado de si se converte em technetoubiou". O sujeito tem como intuito voltar-se para si mesmo, a fim de conhecer a si mesmo. 
do ascetismo pagão ao ascetismo cristão ${ }^{4}$. Ao elencar três etapas da ideia do cuidado de si, Foucault se apropria dos termos filosofia e espiritualidade como uma ferramenta hermenêutica para analisar a formação da subjetivação do sujeito.

Portanto, ao que se refere aos domínios foucaultianos, é possível destacar que o sujeito é o grande eixo das pesquisas do filósofo francês, o qual percebe o conhecimento em três movimentos distintos, a saber: a arqueologia (como hermenêutica das estruturas); a genealogia (como hermenêutica das relações) e a ética (como hermenêutica de si mesmo). Nesse processo epistêmico, desprovido de molduras conceituais, Foucault (ano) atrela a ideia de cuidado de si com a máxima conbece a ti mesmo; com isso, o autor enreda todos os seus domínios no esforço de compreensão do sujeito e da formação da subjetividade de modo holístico. Nesse caminho formativo, a inter-relação do filósofo (que passaremos a descrever como educador) era imprescindível. Cabe ao educador o papel de auxiliar o indivíduo no processo de formação. Nessa trajetória formativa três conceitos ganham destaque na moldura teórica foucaultiano: subjetivação, filosofia e espiritualidade, que serão apresentados na sequência.

\section{2 - SUBJETIVIDADE, FILOSOFIA E ESPIRITUALIDADE EM FOUCAULT}

Na obra foucaultiana, como já foi mencionado, o sujeito é sempre o grande eixo central de análise. O sujeito, para Foucault (ano), está além dos moldes empíricos ou estruturas sociais. O ser não é uma consequência de um estruturalismo determinístico. É um ser ativo, de abalroamento, de remodelação a partir das conexões existenciais criadas. A subjetividade está nesse imbróglio.

\footnotetext{
4 A terceira etapa é a passagem do ascetismo pagão ao ascetismo cristão nos séculos IV e V. (FOUCAULT, ANO, p. 137). Já no ascetismo pagão para o ascetismo cristão a ideia não é o sujeito voltar para si. Em vez disso, implica a ruptura e a renúncia a si mesmo, uma espécie de purificação de si mesmo por meio da obediência, diferente da ideia de conversão e mudança, presente no helenismo romano, que pretendia fazer com que o sujeito chegasse ao patamar de 'senhor de si mesmo'.
} 
Por subjetividade Foucault denomina "a maneira pela qual o sujeito faz experiência de si mesmo num jogo de verdade, no qual ele se relaciona consigo mesmo" (FOUCAULT, apud REVEL, 2002, p. 85). É nesse jogo de técnicas de si para si que a subjetividade é apropriada pelo sujeito, "o lugar da invenção do si não está no exterior da grade do saber/poder, mas na sua torção íntima - e o percurso filosófico de Foucault parece aí, para nós, disso dar exemplo" (REVEL, 2002, p. 85).

Ao que se refere à Filosofia, Foucault (2006, p. 19) transcende os conceitos elementares, convencionais e até mesmo tradicionais ao escrever:

Chamemos de 'filosofia', se quisermos, esta forma de pensamento que se interroga, não certamente sobre o que é verdadeiro e sobre o que é falso, mas sobre o que faz com que haja e possa haver verdadeiro e falso, sobre o que nos torna possível ou não separar o verdadeiro do falso. Chamemos de 'filosofia' a forma de pensamento que se interroga sobre o que permite ao sujeito ter acesso à verdade, forma de pensamento que tenta determinar as condições e os limites de acesso do sujeito à verdade.

O primeiro destaque ao que se refere à definição do autor é a despreocupação da filosofia em afirmar categoricamente o que é verdadeiro e falso. Se durante muitos séculos os filósofos e cientistas tentaram discernir com precisão o que é genuíno do errôneo, Foucault (ano), por sua vez, não se preocupa com a definição do termo em si. Em vez disso, ele aponta que o mais relevante é compreender o que leva o sujeito a nominar determinado evento ou fenômeno de verdadeiro ou errado. A preocupação da filosofia foucaultiana está na consciência que compõe a subjetivação do sujeito. $\mathrm{O}$ destaque de sua definição encontra-se na forma de alterar o ponto de partida para o processo reflexivo e analítico.

Outro aspecto que salta na definição do filósofo está na expressão "forma de pensamento que se interroga sobre o que permite ao sujeito ter acesso à verdade" (FOUCAULT, 2006, 
p. 19). Nessa afirmação, Foucault demonstra que o trabalho da filosofia não está em encontrar respostas, mas, em problematizar, questionar, arguir sobre a constituição e a subjetivação do sujeito a fim de que a verdade saia de um espaço meramente metafísico.

Ainda no que tange à filosofia Foucault (2006, p. 19)) aponta que a filosofia é "a forma de pensamento que tenta determinar as condições e os limites de acesso do sujeito à verdade". Nessa última afirmação, o pressuposto básico é a interação com as potencialidades e limitações inerentes ao ser humano na busca da verdade.

O filósofo define a filosofia como 'forma de pensamento'. Em seguida seu esforço é apresentar a definição de espiritualidade, entendida como (2006, p. 3):

... o conjunto de buscas, práticas e experiências tais como as purificações, as asceses, as renúncias, as conversões do olhar, as modificações da existência, etc., que constituem, não para o conhecimento, mas para o sujeito, para o ser mesmo do sujeito, o preço a pagar para ter acesso a verdade.

Para o filósofo, a ideia de espiritualidade está inter-relacionada com o pressuposto de o sujeito estar em relação consigo mesmo. É por meio da espiritualidade que o sujeito se desprende de ídolos pré-estabelecidos e tem um esforço significativo em direção à verdade, pois, segundo Sugizaki (2008, p. 210) “a espiritualidade é o que diz respeito às transformações que o sujeito deve sofrer para ter acesso à verdade". Tendo como ponto de partida a espiritualidade do Ocidente, Foucault (2006) categoriza três pontos importantes na espiritualidade.

O primeiro aspecto está relacionado à ideia de que a espiritualidade não é algo natural ao sujeito, mas sempre tarefa a fazer-se. Em outras palavras, é uma força externa que atrai o indivíduo, afim de que, ao deslocar o sujeito de si mesmo, possa, nessa tensão, lançá-lo para dentro de si, haja vista que:

A espiritualidade postula que a verdade jamais é dada de pleno direito ao sujeito. A espiritualidade postula que o 
sujeito enquanto tal não tem direito, não possui capacidade de ter acesso à verdade. Postula que a verdade jamais é dada ao sujeito por um simples ato de conhecimento, ato que seria fundamentado e legitimado por ser ele o sujeito e por ter tal e qual estrutura de sujeito. Postula a necessidade de que o sujeito se modifique, se transforme, se desloque, torne-se, em certa medida e até certo ponto, outro que não ele mesmo, para ter direito a [o] acesso à verdade. A verdade só é dada ao sujeito a um preço que põe em jogo o ser mesmo do sujeito. Pois, tal como ele é, não é capaz de verdade (FOUCAULT, 2006, p. 19-20)

O segundo aspecto elencado por Foucault (2006) sobre espiritualidade na antiguidade ocidental está vinculado com a premissa de que o sujeito carece de um movimento de conversão. Para o autor, só há verdade se houver uma grande conversão ou transformação do sujeito. $\mathrm{O}$ devir se torna um imperativo ao passo que equaciona dois termos fundantes na constituição do sujeito, bem como para a espiritualidade, a saber: éros (amor) e áskesis (ascese). Se por um lado o sujeito é explosão de sentimentos, de pulsões, de amor, por outro, tal processo se torna legítimo na jornada do si para si mesmo. Esse devir transforma o sujeito e sua subjetivação, como destaca Foucault (2006, p. 20):

Há um movimento que 'arranca o sujeito de seu status e de sua condição atual (movimento de ascensão do próprio sujeito, movimento pelo qual, ao contrário, a verdade vem até ele e o ilumina). Chamaremos este movimento, também muito convencionalmente, em qualquer que seja seu sentido, de movimento éros (amor). Além desta, outra grande forma pela qual o sujeito pode e deve transformar-se para ter acesso à verdade é um trabalho. Trabalho de si para consigo, elaboração de si para consigo, transformação progressiva de si para consigo em que se é o próprio responsável por um longo labor que é o da ascese (áskesis). ÉROS e ÁSKESIS, as duas grandes formas com que, na espiritualidade ocidental, concebemos as modalidades 
segundo as quais o sujeito deve ser transformado para, finalmente, tornar-se sujeito capaz de verdade.

O terceiro ponto relacionado à espiritualidade da antiguidade ocidental está atrelado à ideia de que a verdade é a iluminação ou esclarecimento (Aufklärung). O destaque está para o pressuposto de que essa iluminação não está na recompensa da ascese, em vez disso, é por meio da iluminação que o sujeito consegue desenvolver a tekhnetoubiou, o que foi denominado por Foucault de retorno da verdade sobre o sujeito, como descreve o filósofo:

Para a espiritualidade, a verdade não é simplesmente o que é dado ao sujeito a fim de recompensá-lo, de algum modo, pelo ato de conhecimento e a fim de preencher este ato de conhecimento. A verdade é o que ilumina o sujeito; a verdade é o que lhe dá beatitude; a verdade é o que lhe dá tranquilidade da alma. Em suma, na verdade e no acesso à verdade, há alguma coisa que completa o próprio sujeito, que completa o ser mesmo do sujeito e que o transfigura (...) para a espiritualidade, um ato de conhecimento, em si mesmo, jamais conseguiria dar acesso à verdade se não fosse preparado, acompanhado, duplicado, consumado por certa transformação do sujeito, não do indivíduo, mas do próprio sujeito no seu ser de sujeito (FOUCAULT, 2006, p. 20-21).

Dessa forma, nas três características da espiritualidade ocidental antiga, identifica-se um processo dialético, pois, aquilo que não é inato do ser humano, que exige uma conversão radical do sujeito, para que, em processo, o sujeito possa ser iluminado em sua jornada a si mesmo e encontre o sentido do que é o conhecer a ti mesmo como um desdobramento do cuidado de si, estabelece uma aproximação quase inexorável entre verdade e espiritualidade, pois é perceptível um entrelaçamento profundo entre verdade e espiritualidade. Nessa inspiração, Foucault (2006, p.24) problematiza: 
...se definirmos a espiritualidade como o gênero de práticas que postulam o sujeito, tal como ele é, não é capaz de verdade, mas que a verdade, tal como ela é, é capaz de transfigurar e salvar o sujeito, diremos então que a idade moderna nas relações entre sujeito e verdade começa no dia em que postulamos o sujeito, tal como ele é, é capaz de verdade, mas que a verdade, tal como ela é, não é capaz do sujeito.

O excerto sugere que, para Foucault (2006), a verdade não é arbitrária, consolidada ou cristalizada. Em outras palavras, a verdade não é o ser ativo que remodela o sujeito, em vez disso, é o sujeito, em suas mais diversas esferas, que altera a relação com a verdade.

Para resumir este tópico, foi descrito como o sujeito é mais do que as estruturas que o forjam, ou as relações de poder que o influenciam. Na perspectiva foucaultiana, o sujeito é uma explosão de acontecimentos. Assim, três aspectos foram descritos. O primeiro, que trata da subjetividade, é descrito como as diversas experiências que o sujeito tem de si mesmo, como movimentos centrípetos e centrífugos que remodelam o sujeito. $O$ segundo aspecto destacado neste tópico é relacionado ao conceito de filosofia; como foi mencionado anteriormente, a filosofia é uma postura reflexiva não de adjetivações, mas que leva o sujeito à formulação desses adjetivos. Como terceiro aspecto, este tópico conceituou a ideia de espiritualidade por meio de diferentes maneiras, caminhos e possibilidades do sujeito voltar para si, de encontrar transcendências que conduzam à verdade.

Em sua abordagem sobre subjetividade, Filosofia e espiritualidade, Foucault (2006) demonstra que o cuidado de si é uma reivindicação do indivíduo que vive o processo do 'conhece a ti mesmo' com o intuito de confluir com a verdade. Ao estabelecer um paralelo com o processo educativo, pode-se mensurar alguns instrumentais positivos para uma constituição do sujeito em sua plenitude, ou seja, na abordagem foucaultiana, a subjetividade, a 
espiritualidade e a filosofia são elementos que permeiam a constituição do sujeito, panorama que será tratado posteriormente.

\section{3 - CONTRIBUIÇÕES DA FILOSOFIA \\ DA EDUCAÇÃO PARA A CONSTITUIÇÃO DO SUJEITO: PISTAS FOUCAULTIANAS}

O sujeito tem papel central na obra foucaultiana. Por este viés, seguindo os pressupostos de Veiga-Neto (2004), pode-se afirmar que a teoria foucaultiana aponta algumas pistas para o processo educativo contemporâneo. Mais do que delinear os aspectos negativos inerentes à vida da escola, cabe destacar pistas de ressignificação desse espaço de suma importância para a sociedade.

A escola é o ambiente em que toda a população é condicionada a frequentar, uma instituição de sequestro, segundo Foucault (2010b). Independente de credo, gênero, etnia ou status social, a vida escolar é um imperativo inegociável na formação do sujeito contemporâneo. É nesse espaço que a criança vivencia sua infância, que o adolescente enfrenta seus dramas existenciais. Em linhas gerais, as escolas estabelecem nesse espaço um recorte do tempo, intitulado 'agenda do dia'. A justificativa é simples: estabelecer uma rotina na vida da criança, a fim de que ela seja forjada para ser um bom adulto. Há uma mímeses da expectativa do adulto bem sucedido sobre a vida da criança.

O ambiente escolar parece nutrir um tempo fragmentado, haja vista que a criticidade - que é elemento inerente da criatividade - é moldurada a partir das atividades pré-estabelecidas pelo docente responsável pela sala. Surge uma agenda que objetifica os seres. Tal modelo castrador, disciplinar, está ligado com a perspectiva Foucaultiana (2010b) ao descrever o condicionamento da criança a uma vida de simples adequações e respostas a estímulos externos, privando e, até mesmo, castrando o protagonismo criativo imaginativo inerente a uma subjetivação da criança. A formação passa por um viés de deformação, ao passo que não prestigia e privilegia a autenticidade e singularidades.

Seguindo as proposições foucaultianas (FOUCAULT, 2006), a educação precisa ater-se à ideia da 'teknetoubio' (técnica para 
a vida) para auxiliar, desde a mais tenra infância, o sujeito a ter a vontade e o desejo de trilhar um caminho de volta para si. Mencionar o termo 'técnico' em uma sociedade das tecnicidades de alta produção não é sinônimo da proposição de Foucault, pois a técnica sobre a vida está em volta de atividades que auxiliem o sujeito a voltar para si, descobrindo, a partir de si mesmo, as janelas para o mundo.

Outra significativa contribuição foucaultina ao que tange a educação, a partir das proposições de Veiga-Neto (2004), dialoga com um espaço de subjetivações em potencial. A educação deveria romper com as epistemologias cristalizadas pelo racionalismo dedutivo ou pelo empirismo indutivo. É fundamental vivenciar a subjetividade, que é um ato de experienciar o si mesmo. Se por um lado há uma tendência de fragmentação do eu para uma heteronomia impositiva, é possível identificar, por outro lado, uma alternativa de condicionamento social rumo a uma vida criativa em que há apropriação do si mesmo.

Foucault (2006) não isola o ser do mundo em que vive. Não descarta as relações; pelo contrário, aponta que as relações emancipatórias são aquelas que auxiliam o sujeito na conquista de sua autonomia justamente porque vivenciou o encontro com o outro. Estar em relação é o que potencializa a saída do sujeito dos enclausuramentos existenciais para uma vida autônoma.

Tanto a filosofia como a espiritualidade são instrumentais relevantes. Como já foi mencionado, a espiritualidade representa o start para a transcendência, um instrumental importante para conhecer a verdade.

Portanto, conforme a proposta de Foucault (2006) e as releituras de Deleuze (2005) e Veiga-Neto (2004) não cabe ao/à educador/a levar uma verdade epistemologicamente aceita e deferida pelo mundo da verificabilidade. Cabe a esse/a a empreitada de auxiliar o/a educando no caminho de retorno a si (FOUCAULT, 2006), com técnicas que embelezem a vida e apropriem o/a educando/a, pois, ao encontrar consigo, percebe o mundo que está para além dele, ou, em sentido inverso, o mundo externo faz com que haja o desejo do encontro consigo mesmo. 
Mais do que encontrar fórmulas para bons rendimentos, ou alta produtividade - pressão inerente ao século XXI - cabe aquele/a que se propõe a educar não deformar, isto é, encontrar caminhos para que o sujeito saia da condição de coadjuvante para autor/ator de si.

Por fim, este artigo se deteve em apresentar como o sujeito faz parte do grande eixo do pensamento de Foucault (ano). O seu conhecimento pode ser dividido em três domínios, conforme sistematizado por Veiga-Neto (2004), que são: ser/saber (arqueologia), ser/poder (genealogia); ser/ético (ética). Como segunda intenção deste artigo, foram propostos três aspectos potencializadores do processo de conbece a ti mesmo, a saber: a subjetividade (o experienciar a si mesmo), a filosofia (a interrogação sobre o que faz pensar o que se pensa), a espiritualidade (como os caminhos que despertam a subjetividade e a filosofia).

Em suma, buscou-se demonstrar que, em uma sociedade modelada pelas tecnicidades de epistemologias arbitrárias, é fundamental encontrar caminhos que despertem o retorno de si intermediado pelo outro.

\section{REFERÊNCIAS}

BARROS, João Roberto. Epimeleia Heautou Helenística em Foucault: Universalização da Espiritualidade. Sergipe: Filosofia em Revista Prometeus Viva Vox - ano 5 - Número 9 - Janeiro-Junho/2012. p. 9-25. Disponível em: < https://seer.ufs.br/index.php/prometeus/article/viewFile/781/677>. Acesso em: 13 Agosto 2018.

DELEUZE, Giles. Foucault. Tradução Claudia Sant'Anna Martins. Revisão da tradução Renato Janine Ribeiro. São Paulo: Editora Brasiliense, 2005.

FOUCAULT, Michel. A Hermenêutica do Sujeito. Tradução Márcio Alves da Fonseca e Salma Tannus Muchail São Paulo: Martins Fontes, 2006.

2010a.

, Michel. O Governo de si e dos outros. São Paulo: Martins Fontes,

, Michel. Vigiar e Punir: história da violência nas prisões. Tradução de Raquel Ramalhete. Petrópolis: Vozes, 2010b. 
, Michel. História da Sexualidade 3. Tradução Maria Thereza da Costa Albuquerque e J. A. Guilhon Albuquerque. O cuidado de Si. São Paulo: Graal, 2005.

MACHADO, Roberto. Foucault, a ciência e o saber. Rio de Janeiro: Zahar, 2007.

NIETZSCHE, Fredrich. Assim falou Zaratrustra: um livro para todos e para ninguém. Tradução, notas e posfácio de Paulo César de Souza. São Paulo: Cia das Letras, 2011.

REVEL, Judith. Foucault: Conceitos essenciais. Tradução Carlos Piovezani Filho e Nilton Milanez, Revisão técnica Maria do Rosário Gregolin. São Carlos: Editora Clara Luz, 2002, 93 p.

RIBEIRO, Darcy. O povo brasileiro: a formação e o sentido do Brasil. São Paulo: Global Editora, 2015.

SUGIZAKI, Eduardo; ROSA, Mario F. A espiritualidade ontem e hoje. Foucault e a hermenêutica de si. Diálogos (Im)pertinentes - Dossiê Religiosidade II. In. Revista Abordagem Gestalt - XIV (2): 205-212, jul-dez, 2008. Disponível em: < http://pepsic.bvsalud.org/pdf/rag/v14n2/v14n2a08.pdf>. Acesso em: 13 agosto 2018.

VEIGA-NET0, Alfredo. Foucault e a Educação. 2 ed. Belo Horizonte: Autência, 2004.

Alfredo. A ordem das Disciplinas. Tese de Doutorado. Universidade Federal do Rio Grande do Sul, Faculdade de Educação. Programa de Pós-Graduação em Educação. Porto Alegre, 1996. Disponível em: < https://www. lume.ufrgs.br/handle/10183/131158>. Acesso em: 13 agosto 2018. 